\title{
Reproducibility of Heart Rate Variability Revealed by Repeated Measurements during and after Hemodialysis
}

\author{
Kerstin Deussing ${ }^{\mathrm{a}}$ Ralph Wendt ${ }^{\mathrm{a}}$ Ronald Burger ${ }^{\mathrm{b}} \quad$ Maik Gollasch $^{\mathrm{c}, \mathrm{d}}$ \\ Joachim Beige ${ }^{\mathrm{a}, \mathrm{e}}$ \\ ${ }^{a}$ Department of Nephrology and Kuratorium for Dialysis and Transplantation (KfH) Renal Unit, Hospital St.

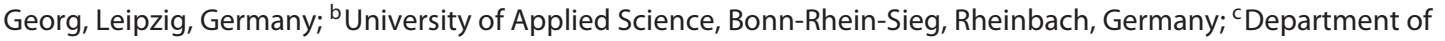 \\ Nephrology and Intensive Care, Charité Universitätsmedizin, Berlin, Germany; ${ }^{d}$ Experimental and Clinical Research \\ Center (ECRC), Charité, Universitätsmedizin Berlin, Max-Delbrück Center for Molecular Medicine (MDC), Berlin, \\ Germany; ${ }^{e}$ Martin-Luther-University Halle, Wittenberg, Germany
}

\section{Keywords}

Dialysis · Heart rate variability · Intradialytic morbid event · Low-frequency to high-frequency · Autonomous nervous system · Sympathetic activation

\section{Abstract \\ Background/Aims: Trajectory of heart rate variability (HRV) represents a noninvasive real-time measure of autonomous nervous system (ANS) and carries the capability of providing new insights into the hemodynamic compensation reserve during hemodialysis (HD). However, studies on HRV repro- ducibility during HD are scarce and did not refer to different reading periods. In this observational study, we aimed to es- tablish the best suited and most reliable and reproducible HRV index in routine HD treatments including different read- ing rates. Methods: HRV was characterized by standardized mathematical variation expressions of $R / R^{\prime}$ intervals: $S D$ of all $R / R^{\prime}$ intervals (ms), square root of the root mean square of the sum of all differences between adjacent $R / R^{\prime}$ intervals (ms), percentage of consecutive $R / R^{\prime}$ intervals that differ by $>50$ ms (\%), low-frequency spectral analysis HRV (LF, ex- pressing sympathetic activity), and high-frequency HRV (HF,}

expressing parasympathetic activity). To compare robustness of these HRV indices during HD procedures, we compared HRV indices means between different HD sessions and controlled for association with clinical parameters. Results: In 72 HD treatments of 34 patients, we detected the highest reproducibility (89\%) of HRV measures when analyzing the low-frequency to high-frequency (LF/HF) ratio in long-term $(3 \mathrm{~h})$ readings. Long-term LF/HF was able to discriminate between patients with and without heart failure NYHA classes $\geq 3$ ( $p=0.009$ ) and type 2 diabetes ( $p=0.023$ ). We were unable to study relationships between ANS and intradialytic complications because they did not appear in our cohort. Short-term readings of HRV indices did not show any significance of pattern change during HD. Conclusion: In summary, our data provide evidence for high robustness of longterm LF/HF in analyzing HRV in HD patients using future automated monitoring systems. For short-term analysis, mathematical real-time analysis must evolve.

(c) 2019 S. Karger AG, Basel

K.D. and R.W. contributed equally to the manuscript.

\section{KARGER}

(c) 2019 S. Karger AG, Basel

karger@karger.com

www.karger.com/bpu
Joachim Beige

Deptartment of Nephrology, Kuratorium for Dialysis and Transplantation

Hospital St. Georg, Delitzscher Street 141 (Haus 54)

DE-04129 Leipzig (Germany)

E-Mail Joachim.Beige@ sanktgeorg.de 


\section{Background}

Hemodialysis (HD) is a therapeutical approach associated with circulatory and pathophysiological changes impacting the patient's well-being and outcome but at the same time providing life-sustaining detoxification and fluid removal. To achieve noncomplicated HD procedures, in recent years, attention has been paid to balancing relative blood volume (rBV) trajectory and adequate ultrafiltration with the ultimate goal to reduce the frequency of intradialytic morbid events (IME) [1-7]. In order to avoid IME, a sustained cerebral and organ perfusion by efficient cardiac output is mandatory. This can be maintained as long as sympathetic activity and function of the autonomous nervous systems (ANS) ensure effective cardiac work and vasoconstriction $[8,9]$. Few studies demonstrated the general importance of ANS in this scenario by means of "goldstandard" microneurography [10] (MSNA) during HD [11]. However, this method is invasive and does not allow measurements over longer time periods.

Thus, attempts have been made to monitor the function of ANS by noninvasive and real-time approaches. As such, the dynamics of ANS can be assessed by heart rate variability (HRV) during HD [12-15]. As a result, it has been shown that IME's may culminate within a phase of sudden vagal breakthrough (hypotension, paradoxical bradycardia, and vomiting [13]) after sympathetic activity increased to sustain appropriate peripheral resistance $[12,16]$. Even though this phenomenon can be controlled by volume therapy, it is important to understand that the sympathetic (over-) stimulation for maintaining cardiac output has a long-term sequelae. In chronic kidney disease and sympathetic hyperactivity, a specific vascular morbidity is created $[17,18]$. Insomnia, one of the most important components of the complaint burden of dialysis patients [19] is highly significant associated with ANS [20]. Hypothetically, it can be assumed that increased postdialysis recovery time can be seen as sequelae of (hyper)-sympathetic activity. Taking such reasoning together, a well-tolerated and both acutely and long-term event-free dialysis is associated with freedom from IME as well as sympathovagal balance. While rBV measurement and regulation during dialysis have been widely investigated (for review [21]), little is known about resulting ANS and the link between intradialytic sympathetic activity with long-term morbidity and mortality.

Previous HRV studies in HD patients have shown nonuniform HRV pattern, with possible impact for subgroups of HD patients [8, 13-15, 22, 23]. However, repeated measurements investigating the technical reproducibility of different HRV markers have received little attention so far. We intended to establish a reliable surrogate of ANS which can be used in routine HD treatments and automatically recorded by automated data handling in dialysis management systems. We hypothesized that HRV can be easily measured with high reproducibility and robustness during subsequent HD sessions. The present study was designed to gain data of HRV during and after repeated HD sessions by different reading rates and to control for associations of HRV with patients' comorbidities.

\section{Material and Methods}

\section{HRV Recordings}

Electrocardiographic signals (ECG) measured by eMotion Faros $180^{\circ}$ devices from Mega Electronics Ltd. (Kuopio, Finland) were registered during the last $3 \mathrm{~h}$ of a dialysis session and the first $3 \mathrm{~h}$ after the end of a session $(1,000 \mathrm{~Hz})$ and transferred to a personal computer. Kubios free HRV software of the Biosignal Analysis and Medical Imaging Group (University of Kuopio, Finland) and Cardiscope Analytics Software (Gloucestershire, UK) were used for preparation and further analysis of standard $\mathrm{HRV}$ indices including artifact correction (SD of all R/R' intervals [SDNN, ms], square root of the root mean square of the sum of all differences between adjacent R/R' intervals [RMSSD, $m s$ ], percentage of consecutive R/R' intervals that differ by $>50 \mathrm{~ms}$ [pNN50,\%], low-frequency spectral analysis HRV [LF], and high-frequency HRV [HF]).

Patient Population, Data Acquisition, and Statistics

This observational study was carried out between June and October 2015 on 34 voluntary maintenance HD patients aged 29-77 years (23 male, median age 57 years, 6 with diabetes, 8 with NYHA [24] classification $\geq 2,5$ with coronary artery disease [CAD]; Table 1). Patients confirmed participation agreement by signing informed consent sheets (Ethical Committee vote \#EK-BR-42/11-1). Repeated HRV data reading was performed in repeated dialysis sessions within the same week excluding long week-end intervals.

Patients with heart failure NYHA class $\geq 3$ or NYHA class 2 plus 1 further comorbidity (diabetes or CAD) or NYHA class 1 or 0 plus 2 other comorbidities were defined having high cardiovascular comorbidity profile.

In linear regression analyses and ANOVA, covariates were analyzed by a nonconditional overall model using comorbidity status or HRV indices as dependent. Readings of HRV were used for ANOVA after logarithmization following non-normal distribution. Group comparison of categorical values was computed by contingency tables and chi-square, whereas numerical values were compared by one-factorial ANOVA and independent $t$ test.

\section{Results}

Within the study period of 34 participating patients (see description table) and $72 \mathrm{HD}$ sessions, no IME occurred. After reviewing all recorded tachograms 
Fig. 1. Boxplot of HRV parameters 25th75th percentile (stars, circles $=$ outliners) during and after HD sessions by comorbidity status. HD, hemodialysis; SDNN, SD of all R/R' intervals; RMSSD, square root of the root mean square of the sum of all differences between adjacent $R / R$ ' intervals; pNN50, percentage of consecutive R/R' intervals that differ by $>50 \mathrm{~ms}$; LF/HF, lowfrequency/high frequency spectral analysis HRV; cv., cardiovascular.
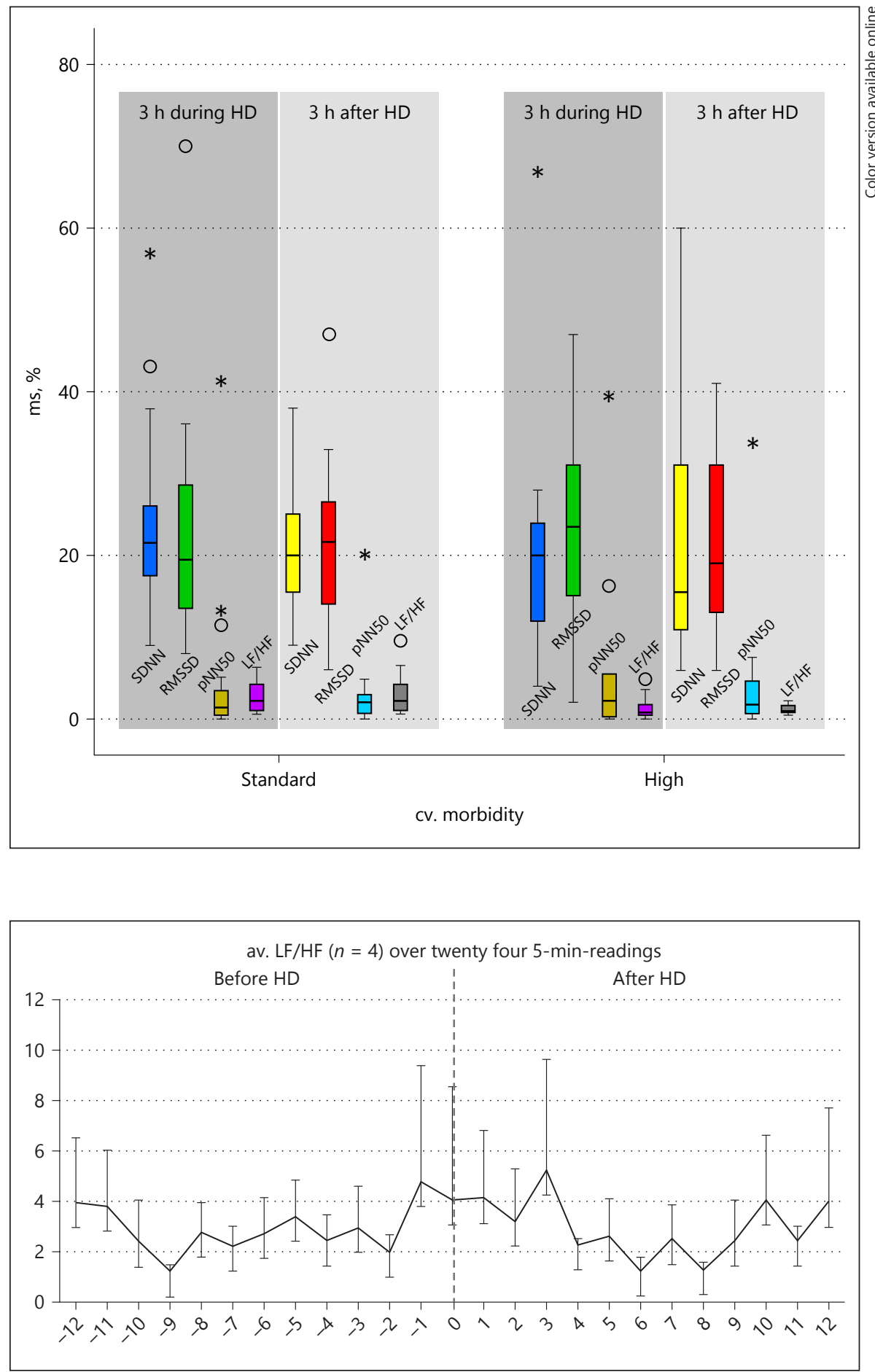

Fig. 2. Average low/high frequency spectral HRV analysis readings of 4 patients from both cardiovascular groups during twelve 5-min-readings $3 \mathrm{~h}$ before and after HD. LF/ $\mathrm{HF}$, low-frequency/high frequency spectral analysis HRV; HD, hemodialysis. by visual analysis, no obvious differences between cardiovascular risk groups of patients were detected (Appendix 1-34; doi 10.6084/m9.figshare.9724715). Overall distribution of standard long-term HRV parameters is displayed by boxplots (Fig. 1). While no sig- nificant pattern changes were notable, the LF/HF ratio decreases slightly after dialysis indicating increased parasympathetic activity (average of 4 patients Fig. 2), which was true in both comorbidity groups (data not shown). 


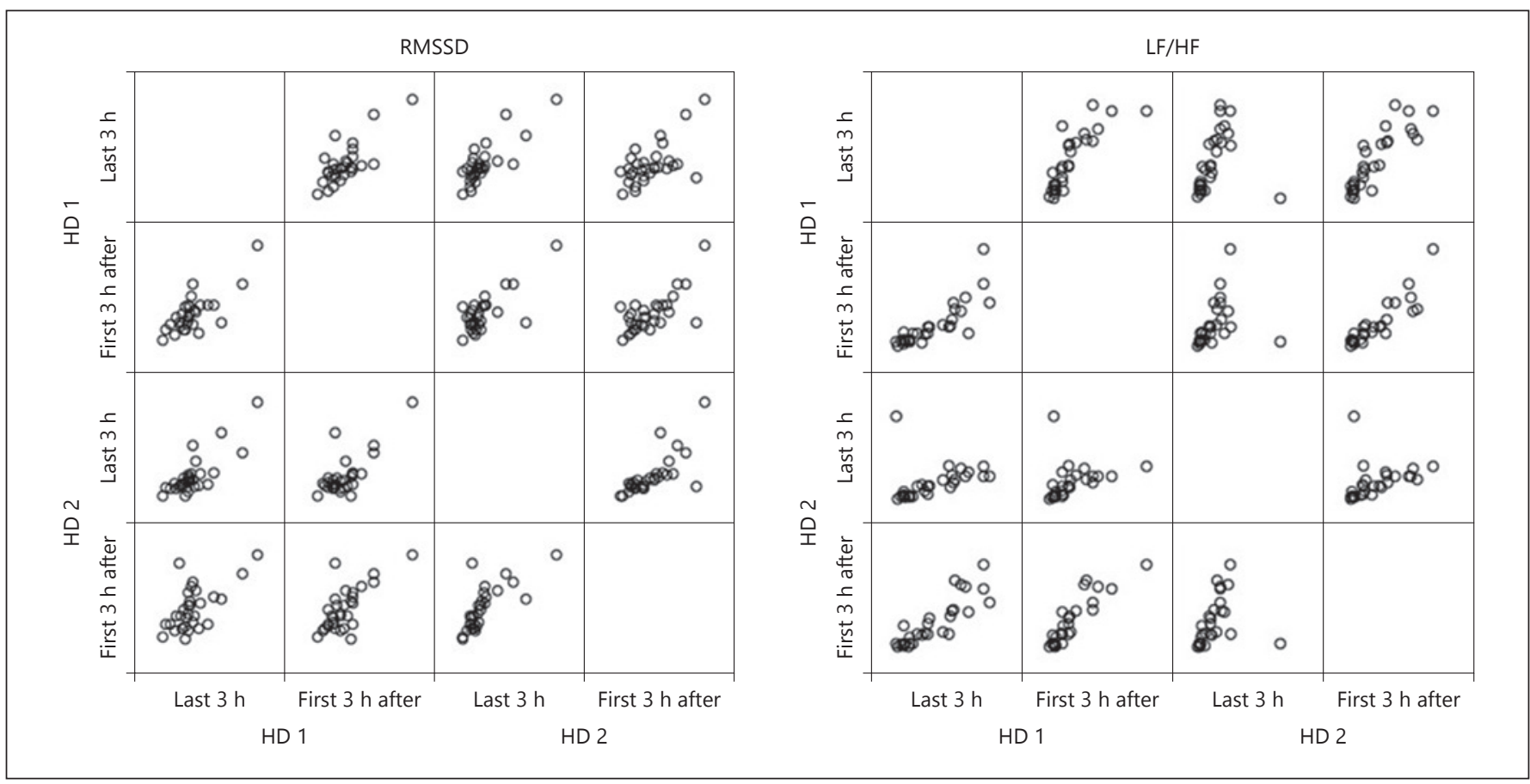

Fig. 3. Distribution of long-term HRV indices during and after HD sessions by comorbidity status. Single data points represent individual patients results during different $3 \mathrm{~h} \mathrm{HD}$ periods. The strongest reproducibility was found for LF/HF after and during $\operatorname{HD}(R=0.89 ; R=0.71)$ and $\mathrm{RMSSD}$ after and during $\mathrm{HD}(R=0.77$;

0.71). SDNNs, RMSSD, pNN50, LF/HF. RMSSD, square root of the root mean square of the sum of all differences between adjacent $\mathrm{R} / \mathrm{R}$ ' intervals; LF/HF, low-frequency/high frequency spectral analysis HRV; HD, hemodialysis.

\section{Analyzing Reproducibility}

Paired $t$ tests of long-term HRV indices $(3 \mathrm{~h})$ and correlation matrix $\mathrm{P}-\mathrm{P}$ ' diagrams during different $\mathrm{HD}$ periods and in repeated sessions showed strongest reproducibility for LF/HF $(R=0.89 ; R=0.71)$ and $\operatorname{RMSSD}(R=$ $0.77 ; 0.71$, Fig. 3$)$.

\section{Long-Term HRV Association with Covariates}

Among all investigated HRV indices, LF/HF was associated with presence of diabetes $(p=0.023)$ and heart failure NYHA classes $(p=0.009)$. Other clinical and anthropometrical parameters (age, gender, time on dialysis, $\mathrm{CAD}$, medication $[\beta$-blocker]) did not show association with any HRV index.

Concerning the association with HD treatment parameters, a multivariate forward regression analysis of $\mathrm{HRV}$ indices within $3 \mathrm{~h} \mathrm{HD}$ yielded weak associations (remaining parameters in the model) of session time with $\mathrm{lg}$ RMSSD ( $\mathrm{B}=-0.008$ [ -0.015 to 0$], p=0.045), \lg \mathrm{LF} / \mathrm{HF}$ $(\mathrm{B}=0.013$ [0.03 to 0.24], $p=0.05)$ and lgpNN50 ( $\mathrm{B}=$ -0.015 [ -0.03 to -0.001 ], $p=0.04)$, and of serum HBG with $\operatorname{lgpNN} 50(\mathrm{~B}=-0.39[-0.74$ to -0.49$], p=0.025)$.

To investigate those HRV measures with high reproducibility (SDNN, LF, HF, LF/HF) in shorter readings, distinct shorter time intervals (twelve 5 min intervals and three $1 \mathrm{~h}$ intervals) were computed and displayed before and after HD in 4 exemplary patients. Figures 4-6 show variability being numerically higher compared to courses of R/R' distances. Because no IME were observed, these variations again could not be associated with clinical events. No significant pattern change of short-term indices could be either visualized or computed.

\section{Discussion}

Our data provide evidence for high reproducibility and robustness of long-term LF/HF methodology in analyzing HRV in HD patients using automated monitoring systems. Analysis of long-term LF/HF was able to discriminate between patients with and without NYHA classes $\geq 3$ and type 2 diabetes, while HRV indi- 


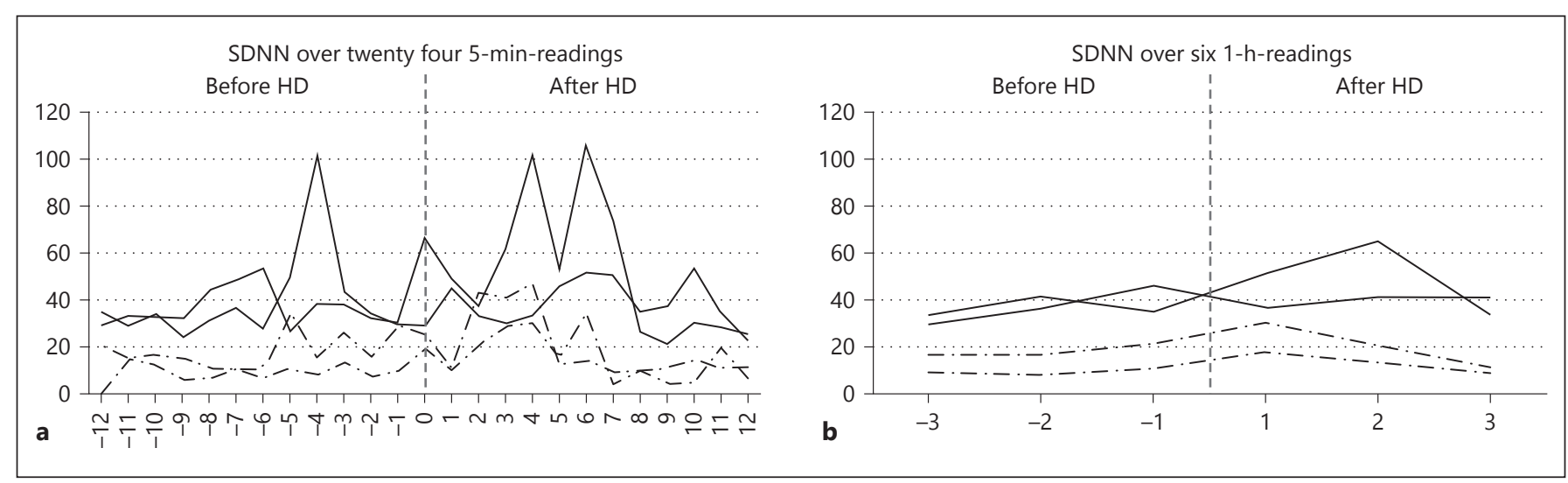

Fig. 4. Individual courses $(n=4)$ of SDNN during (a) twelve 5-min-readings and (b) three 1-h-readings 3 h during and after HD. Individuals belonging to cardiovascular high comorbidity group are marked by broken lines. $\mathrm{SDNN}$, SD of all R/R' intervals; HD, hemodialysis.

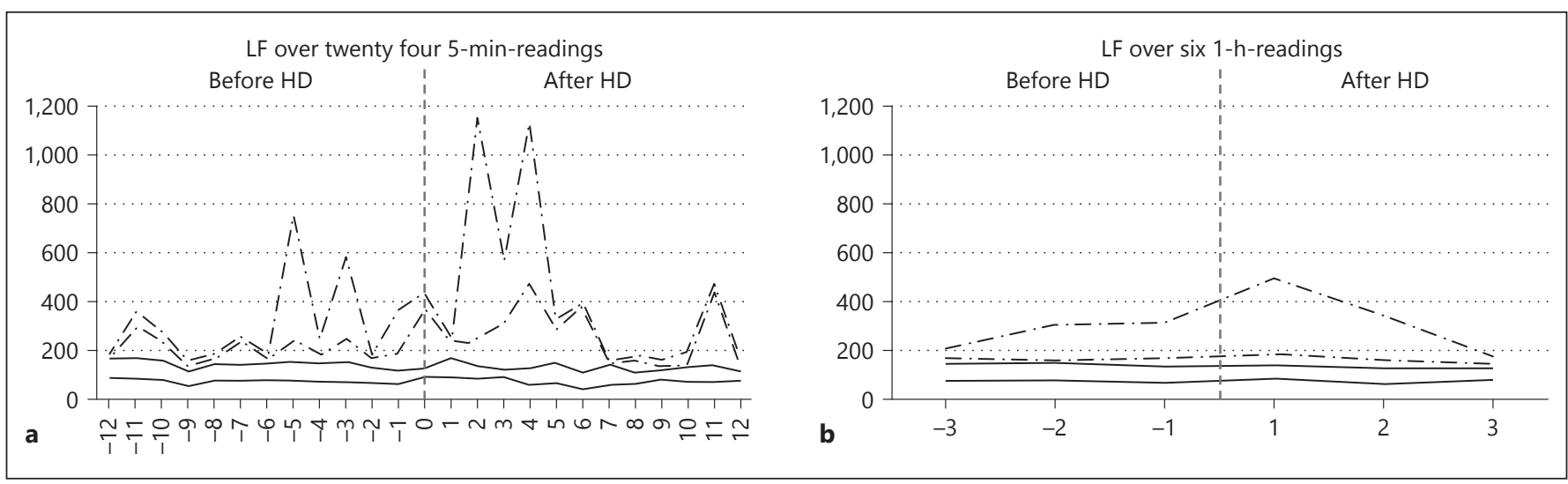

Fig. 5. Individual courses $(n=4)$ of LF during (a) twelve 5 -min-readings and (b) three 1-h-readings $3 \mathrm{~h}$ during and after HD. Individuals belonging to cardiovascular high comorbidity group are marked by broken lines. LF, low-frequency spectral analysis HRV; HD, hemodialysis.

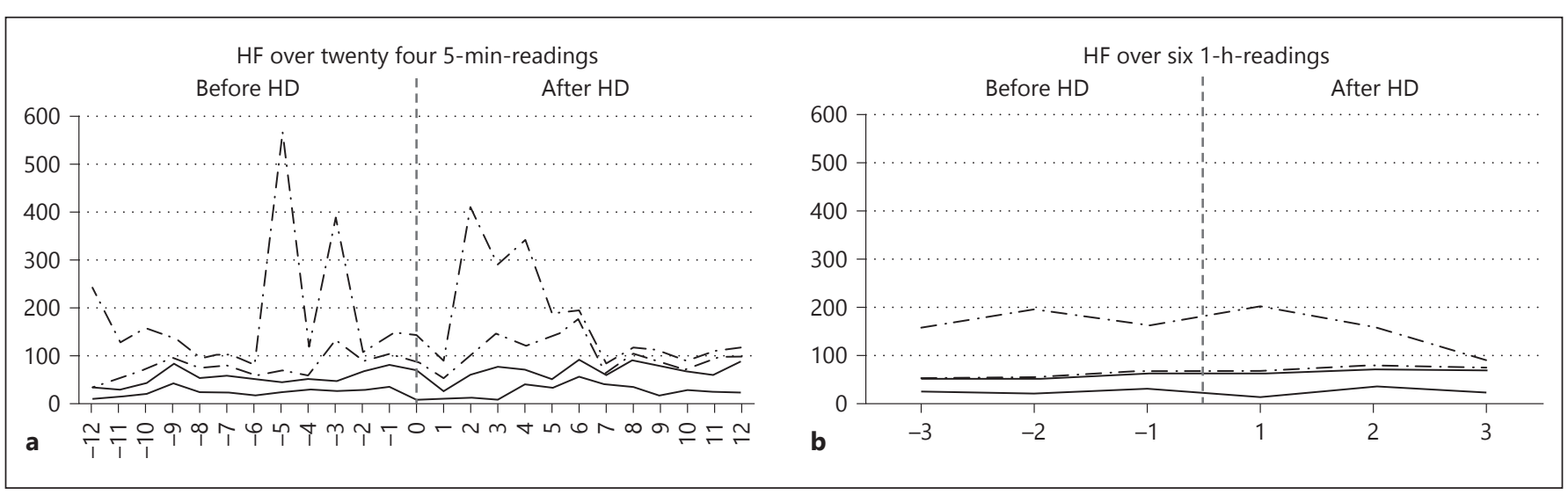

Fig. 6. Individual courses $(n=4)$ of HF during (a) twelve 5-min-readings and (b) three 1-h-readings $3 \mathrm{~h}$ during and after HD. Individuals belonging to cardiovascular high comorbidity group are marked by broken lines. HF, high-frequency HRV; HD, hemodialysis. 
Table 1. Clinical, anthropometrical and dialysis data by comorbidity status

\begin{tabular}{|c|c|c|c|c|}
\hline \multirow[t]{2}{*}{ Parameter } & \multicolumn{3}{|c|}{ Comorbidity status groups } & \multirow[t]{2}{*}{$p$ value } \\
\hline & standard $(n=24)$ & high $(n=10)$ & all $(n=34)$ & \\
\hline Age, years, mean $\pm \mathrm{SD}$ & $52 \pm 14$ & $64.6 \pm 11.6$ & $55.7 \pm 14.4$ & 0.017 \\
\hline Time on HD (vintage years), mean \pm SD & $7.0 \pm 7.0$ & $4.7 \pm 3.8$ & $6.3 \pm 6.2$ & 0.35 \\
\hline Gender, female, $n(\%)$ & $9(38)$ & $2(20)$ & $11(32)$ & 0.28 \\
\hline Diabetes, $n(\%)$ & $2(8)$ & $4(40)$ & $6(18)$ & 0.048 \\
\hline $\mathrm{CAD}, n(\%)$ & $3(12.5)$ & $2(20)$ & $5(14)$ & 0.46 \\
\hline $\mathrm{NYHA} \geq 3, n(\%)$ & $0(0)$ & $8(80)$ & $8(23.5)$ & $<0.0001$ \\
\hline Full-dose $\beta$-block, $n(\%)$ & $2(12)$ & $3(20)$ & $5(15)$ & 0.47 \\
\hline Non-full $\beta$-block, $n(\%)$ & $14(58)$ & $7(70)$ & $21(62)$ & 0.47 \\
\hline $\mathrm{HD}$ session time, mean $\pm \mathrm{SD}$ & $256 \pm 14.4$ & $254 \pm 13.9$ & $255 \pm 14.1$ & 0.72 \\
\hline $\mathrm{UF}, \mathrm{L}$, mean $\pm \mathrm{SD}$ & $1.84 \pm 1.20$ & $2.12 \pm 0.958$ & $1.92 \pm 1.08$ & 0.50 \\
\hline Ideal weight, kg, mean $\pm \mathrm{SD}$ & $74.5 \pm 17.0$ & $79.7 \pm 12.0$ & $76.0 \pm 15.7$ & 0.39 \\
\hline Inter $\mathrm{HD}$ weight gain, $\mathrm{kg}$, mean $\pm \mathrm{SD}$ & $1.5 \pm 1.1$ & $1.8 \pm 1.2$ & $1.6 \pm 1.1$ & 0.51 \\
\hline $\mathrm{Kt} / \mathrm{V}$, mean $\pm \mathrm{SD}$ & $1.5 \pm 0.2$ & $1.5 \pm 0.3$ & $1.5 \pm 0.3$ & 0.78 \\
\hline Phosphorus, mmol/L, mean \pm SD & $2.0 \pm 0.5$ & $1.5 \pm 0.4$ & $1.8 \pm 0.5$ & 0.01 \\
\hline $\mathrm{HBG}, \mathrm{mmol} / \mathrm{L}$, mean $\pm \mathrm{SD}$ & $6.6 \pm 0.6$ & $6.3 \pm 0.6$ & $6.5 \pm 0.6$ & 0.28 \\
\hline $\mathrm{ESA} /$ week, IU, mean $\pm \mathrm{SD}$ & $8,697 \pm 5115$ & $6,788 \pm 5168$ & $8,136 \pm 5128$ & 0.33 \\
\hline BP pre, $\mathrm{mm} \mathrm{Hg}$, mean $\pm \mathrm{SD}$ & $142.7 / 84.6 \pm 22.2 / 12.6$ & $142.8 / 73.9 \pm 24.1 / 11.1$ & $142.7 / 81.4 \pm 22.4 / 12.9$ & $0.99 / 0.03$ \\
\hline $\mathrm{BP}$ after, mm Hg, mean $\pm \mathrm{SD}$ & $138.5 / 78.0 \pm 28.8 / 12.6$ & $138.1 / 73.6 \pm 28.1 / 9.8$ & $138.4 / 76.7 \pm 28.2 / 11.9$ & $0.97 / 0.33$ \\
\hline Heart rate pre, $1 /$ min, mean $\pm S D$ & $78.6 \pm 12.8$ & $74.1 \pm 13.1$ & $77.4 \pm 12.8$ & 0.38 \\
\hline Heart rate after, $1 / \mathrm{min}$, mean $\pm \mathrm{SD}$ & $71.2 \pm 9.2$ & $72.7 \pm 11.4$ & $74.4 \pm 11.6$ & 0.63 \\
\hline
\end{tabular}

$\mathrm{HD}$, hemodialysis; CAD, coronary artery disease.

ces $(3 \mathrm{~h})$ were associated with several treatment parameters. Of note, there were inverse correlations of session time and serum HBG with $\lg$ RMSSD and $\operatorname{lgpNN} 50$ and a direct correlation of session time with $l g \mathrm{LF} / \mathrm{HF}$. Although generally speculative, in particular oppositional correlations of session time with different HRV indices could be seen as an expression of the differing pathophysiological aspects of HRV markers.

While the HRV indices with best reproducibility (LF/ $\mathrm{HF}$ and SDNN) showed huge short-term variability in high-risk patients, we were unable to study relationships between HRV and intradialytic complications because they did not appear in our cohort. Although a slight tendency to increased parasympathetic activity after dialysis was notified by increasing LF/HF, such measures could not be statistically approved, because of interindividual variability. Such phenomenon indicate a general weakness of our study, which was not able to associate random reading rates of every HRV marker of each patient with both time course and IME. With the available software methods of HRV analysis, a random reading-rate HRV analysis is currently not feasible. To evolve the HRV method for HD biofeedback, further mathematical innovations in comprehensive datasets including HD parameters and real-time clinical events are needed.

The observation that 3-h HRV data in repeated HD sessions were strongly correlated (61-89\%) indicates a good reliability of the long-term HRV method during and after dialysis. These long-term data are in line with another long-term HRV study employing repeated measurements (14 patients, 8 male [25]). In this study, ECG measurements were taken at 2 dialysis sessions, and reliability was measured with excellent interclass correlation $>0.85$.

Numerous studies have been performed to test the reliability of short-term HRV ( $5 \mathrm{~min}$ ) in non-HD populations. These studies have shown poor reliability [26-29] presumably related to higher short-term variability like our data. Whether such variability carries a predictive value for major clinical events cannot be addressed by our study because no IME did occur in our cohort.

Of note, lower reproducibility reported by other authors may depend on multiple factors including comorbidities $[15,26,30]$. Related to such reasoning, no intradialytic real-time HRV trajectory is available so far, connecting the continuous display of HRV to other real-time biosignals as for instance $\mathrm{rBV}$ or frequent BP measurements. Such type of interrelated biosignal display could be easily implemented in HD systems by cost-effective technological means. For HRV, only 3 ECG patch electrodes and wiring are needed to be integrated in the HD machine. Following the results of our study, LF/HF seems to represent the most suitable ANS parameter for such an approach. The clinical impact of this real-time technology to predict IME and other outcomes needs to be studied in 
future trials. The large-scale development and validation of structured and interrelated HD patient's biodata may guide HD process by personalized decision support tools.

\section{Acknowledgment}

We acknowledge the help of the KfH Dialysis nursing staff to retrieve data of HRV variability.

\section{Statement of Ethics}

The work presented in that manuscript complies with guidelines for human studies. Ethical approval for this noninvasive descriptive study was gained from the Ethical Committee of the Saxony Board of Physicians (\#EK-BR-42/11-1; see Section "Material and Methods").

\section{Disclosure Statement}

All authors have no conflicts of interest to declare.

\section{Funding Sources}

There was no funding to this work.

\section{Author Contributions}

K.D.: study conception, study design, HRV measurements, HRV analysis, manuscript revision. R.W.: study design, manuscript writing, manuscript revision. M.G.: idea, manuscript writing, manuscript revision. R.B.: study conception, HRV analysis, manuscript revision. J.B.: idea, conception, study design, data analysis, manuscript writing.

\section{References}

1 Antlanger M, Josten P, Kammer M, Exner I, Lorenz-Turnheim K, Eigner M, et al. Blood volume-monitored regulation of ultrafiltration to decrease the dry weight in fluid-overloaded hemodialysis patients: a randomized controlled trial. BMC Nephrol. 2017 Jul; 18(1):238

2 Beige J, Sone J, Sharma AM, Rudwaleit M, Offermann G, Distler A, et al. Computational analysis of blood volume curves and risk of intradialytic morbid events in hemodialysis. Kidney Int. 2000 Oct;58(4):1805-9.

3 Donauer J, Böhler J. Rationale for the use of blood volume and temperature control devices during hemodialysis. Kidney Blood Press Res. 2003;26(2):82-9.

4 du Cheyron D, Lucidarme O, Terzi N, Charbonneau P. Blood volume- and blood temperature-controlled hemodialysis in critically ill patients: a 6-month, case-matched, open-label study. Blood Purif. 2010;29(3): 245-51.

5 Raimann JG, Chan CT, Daugirdas JT, Depner T, Gotch FA, Greene T, et al.; Frequent Hemodialysis Network (FHN) Trial Group. The Effect of Increased Frequency of Hemodialysis on Volume-Related Outcomes: A Secondary Analysis of the Frequent Hemodialysis Network Trials. Blood Purif. 2016;41(4):27786.

6 Steuer RR, Leypoldt JK, Cheung AK, Harris $\mathrm{DH}$, Conis JM. Hematocrit as an indicator of blood volume and a predictor of intradialytic morbid events. ASAIO J. 1994 Jul-Sep;40(3): M691-6.

7 Leypoldt JK, Cheung AK, Steuer RR, Harris $\mathrm{DH}$, Conis JM. Determination of circulating blood volume by continuously monitoring hematocrit during hemodialysis. J Am Soc Nephrol. 1995 Aug;6(2):214-9.
8 Rubinger D, Backenroth R, Sapoznikov D. Sympathetic nervous system function and dysfunction in chronic hemodialysis patients. Semin Dial. 2013 May-Jun;26(3):333-43.

9 Kammel R, Beige J, Czygan M, Birnbaum K, Gleisberg O, Pretschner A, et al. Monitoring the Activation of the Sympathetic Nervous System to Improve Hemodialysis Processes. Biomed Tech (Berl). 2013 Aug;58 Suppl 1:/j/ bmte.2013.58.issue-s1-I/bmt-2013-4225/ bmt-2013-4225.xml.

10 Mano T, Iwase S, Toma S. Microneurography as a tool in clinical neurophysiology to investigate peripheral neural traffic in humans. Clin Neurophysiol. 2006 Nov;117(11):2357-84.

11 Hausberg M, Kosch M, Harmelink P, Barenbrock M, Hohage H, Kisters K, et al. Sympathetic nerve activity in end-stage renal disease. Circulation. 2002 Oct;106(15):1974-9.

12 Maeda K, Fujita Y, Shinzato T, Vega BV, Nakane $\mathrm{K}$, Morita $\mathrm{H}$, et al. Change in sympathetic activity before, during, and after dialysisinduced hypotension. ASAIO Trans. 1990 Jul-Sep;36(3):M462-4.

13 Barnas MG, Boer WH, Koomans HA. Hemodynamic patterns and spectral analysis of heart rate variability during dialysis hypotension. J Am Soc Nephrol. 1999 Dec;10(12): 2577-84.

14 Christensen JH. Cardiac autonomic dysfunction in hemodialysis patients assessed by heart rate variability. Minerva Urol Nefrol. 2012 Sep;64(3):191-8.

15 Ferrario M, Raimann JG, Larive B, Pierratos A, Thijssen S, Rajagopalan S, et al.; Frequent Hemodialysis Network (FHN) Trial Group. Non-Linear Heart Rate Variability Indices in the Frequent Hemodialysis Network Trials of Chronic Hemodialysis Patients. Blood Purif. 2015;40(1):99-108.
16 Pelosi G, Emdin M, Carpeggiani C, Morales MA, Piacenti M, Dattolo P, et al. Impaired sympathetic response before intradialytic hypotension: a study based on spectral analysis of heart rate and pressure variability. Clin Sci (Lond). 1999 Jan;96(1):23-31.

17 Kaur J, Young BE, Fadel PJ. Sympathetic Overactivity in Chronic Kidney Disease: consequences and Mechanisms. Int J Mol Sci. 2017 Aug; 18(8):E1682.

18 Kotanko P. Cause and consequences of sympathetic hyperactivity in chronic kidney disease. Blood Purif. 2006;24(1):95-9.

19 Mucsi I, Molnar MZ, Ambrus C, Szeifert L, Kovacs AZ, Zoller R, et al. Restless legs syndrome, insomnia and quality of life in patients on maintenance dialysis. Nephrol Dial Transplant. 2005 Mar;20(3):571-7.

20 Carter JR, Grimaldi D, Fonkoue IT, Medalie L, Mokhlesi B, Cauter EV. Assessment of sympathetic neural activity in chronic insomnia: evidence for elevated cardiovascular risk. Sleep (Basel). 2018 Jun;41(6).

21 Leypoldt JK, Cheung AK, Delmez JA, Gassman JJ, Levin NW, Lewis JA, et al. Relationship between volume status and blood pressure during chronic hemodialysis. Kidney Int. 2002 Jan;61(1):266-75.

22 Rubinger D, Revis N, Pollak A, Luria MH, Sapoznikov D. Predictors of haemodynamic instability and heart rate variability during haemodialysis. Nephrol Dial Transplant. 2004 Aug;19(8):2053-60.

23 Chan CT, Chertow GM, Daugirdas JT, Greene TH, Kotanko P, Larive B, et al. Effects of daily hemodialysis on heart rate variability: results from the Frequent Hemodialysis Network (FHN) Daily Trial. Nephrol Dial Transplant. 2014 Jan;29(1): $168-78$. 
24 Hunt SA, Abraham WT, Chin MH, Feldman AM, Francis GS, Ganiats TG, et al.; American College of Cardiology; American Heart Association Task Force on Practice Guidelines; American College of Chest Physicians; International Society for Heart and Lung Transplantation; Heart Rhythm Society. ACC/AHA 2005 Guideline Update for the Diagnosis and Management of Chronic Heart Failure in the Adult: a report of the American College of Cardiology/American Heart Association Task Force on Practice Guidelines (Writing Committee to Update the 2001 Guidelines for the Evaluation and Management of Heart Failure): developed in collaboration with the American College of Chest Physicians and the Interna- tional Society for Heart and Lung Transplantation: endorsed by the Heart Rhythm Society. Circulation. 2005 Sep;112(12):e154-235.

25 da Silva DM, Macedo MC, Lemos LB, Vieira FC, Pirôpo US, Andrade HB, et al. Reliability analysis of the heart autonomic control parameters during hemodialysis sessions. Biomed Tech (Berl). 2016 Dec;61(6):623-30.

26 Cipryan L, Litschmannova M. Intra-day and inter-day reliability of heart rate variability measurement. J Sports Sci. 2013;31(2):150-8.

27 Maestri R, Pinna GD, Porta A, Balocchi R, Sassi R, Signorini MG, et al. Assessing nonlinear properties of heart rate variability from shortterm recordings: are these measurements reliable? Physiol Meas. 2007 Sep;28(9):1067-77.
28 Tannus LR, Sperandei S, Montenegro Júnior RM, Carvalho VR, Pedrosa HC, Félix MT, et al. Reproducibility of methods used for the assessment of autonomous nervous system's function. Auton Neurosci. 2013 Oct;177(2): 275-9.

29 Baumert M, Sacre JW. Heart rate complexity and cardiac sympathetic dysinnervation in patients with type 2 diabetes mellitus. Conf Proc Annu Int Conf IEEE Eng Med Biol Soc IEEE Eng Med Biol Soc Annu Conf. 2013; 2013:5570-3.

30 Sandercock GR, Bromley PD, Brodie DA. The reliability of short-term measurements of heart rate variability. Int J Cardiol. 2005 Sep; 103(3):238-47. 